\title{
A brincadeira la ursa, visualidades e peripécias
}

Camilo de Figueiredo Aranha

\section{Resumo}

Esta pesquisa teve como objeto de estudo as visualidades e as peripécias transgressoras do folguedo "la ursa", no bairro do Rangel, em João Pessoa- PB. Trata-se de um estudo de caso, de abordagem qualitativa, do tipo etnográfico, que contou com coleta dados, entrevistas, registos imagéticos e observação direta da atuação de dois grupos de folguedo, um Espontâneo e outro Profissional. É uma investigação fundamentada em referenciais teóricos da Cultura Visual e da Antropologia do cotidiano, que analisa os processos de hibridização do La ursa, sua formação multicultural e a influência da cultura imagética midiática contemporânea exercida nesse entretenimento. O estudo concluiu que esta prática cultural, se reproduz e atua no processo histórico e social presente, resignificando o conhecimento informal e não formal organizado, mediado pelas relações humanas e suas inter-relações simbólicas a partir do ato de brincar.

\section{Palavras chave}

la ursa, visualidades, cultura visual.

\section{The popular playing joke la ursa (the bear), visualities and adventures}

\begin{abstract}
This research aims to study the visualities and transgressive adventures of the popular playing joke "la ursa" (the bear) held at Rangel district, João Pessoa - PB. This is an ethnographic qualitative case study, which included data collection, interviews, image records and direct observation of the performance of two groups of this popular playing joke: one spontaneous and the other professional. This is a research based on theoretical frameworks of Visual Culture and Anthropology of everyday life, which analyzes the processes of hybridization of "la ursa", their multicultural formation and the influence of contemporary media image carried out in that entertainment. The study concluded that this cultural practice reproduces and operate in this historical and social process, reframing non-formal and informal knowledge, mediated by human relationships and their symbolic interrelationships from the act of playing.
\end{abstract}

Keywords

la bear, visual arts, visual culture.

\section{O la ursa}

É um espetáculo performático popular, encontrado em Estados da região nordeste do Brasil, geralmente em períodos pré-carnavalescos. Estudos de Katarina Real(1967), sugerem que a brincadeira de "la ursa" foi trazida da Europa por trabalhadores italianos para o país, no período colonial, e passado por um processo de hibridização com outros folguedos da cultura local nordestina, como bumba meu boi, reisado, caboclinhos entre outros, até chegar no formato atual.

A chegada da "la ursa" a capital paraibana, segundo a versão de Wills Leal (2000), estão associadas a fatos históricos ligados à política e ao desenvolvimento e socioeconômico do estado, no início do Século XX, que trouxe grandes investimentos para a infraestrutura, como também novos meios de entretenimento, como circos e companhias de teatro, 
apresentando atrações como a "la ursa" vinda da África. Como ressalta o autor,

[...] começou a surgir um tipo novo de gaiato. Era o "urso", normalmente acompanhado de um conjunto de pau-de-corda, com roupas de estopa e muita gritaria. 0 bicho aos berros, anunciava: „Viemos da África/ Para o Brasil/ trouxemos um Urso/ Para Divertir"; e a zorra era geral. De casa em casa, com uma cuia (de queijo do Reino), pedindo apoio para o "urso", ou um traguinho para os carnavalescos (LEAL, 2000, p.35).

Assim, em vista dos relatos de Wills Leal, acreditamos que os entretenimentos citados foram os responsáveis pela difusão desse personagem na cidade de João Pessoa, incorporando-se às manifestações carnavalescas da cidade. Desde então, todos os anos, essa brincadeira absorve um crescente número de pessoas que trabalham na construção e na produção das visualidades desse folguedo. Tornou-se parte das tradições e das manifestações culturais carnavalescas de rua dessa cidade.

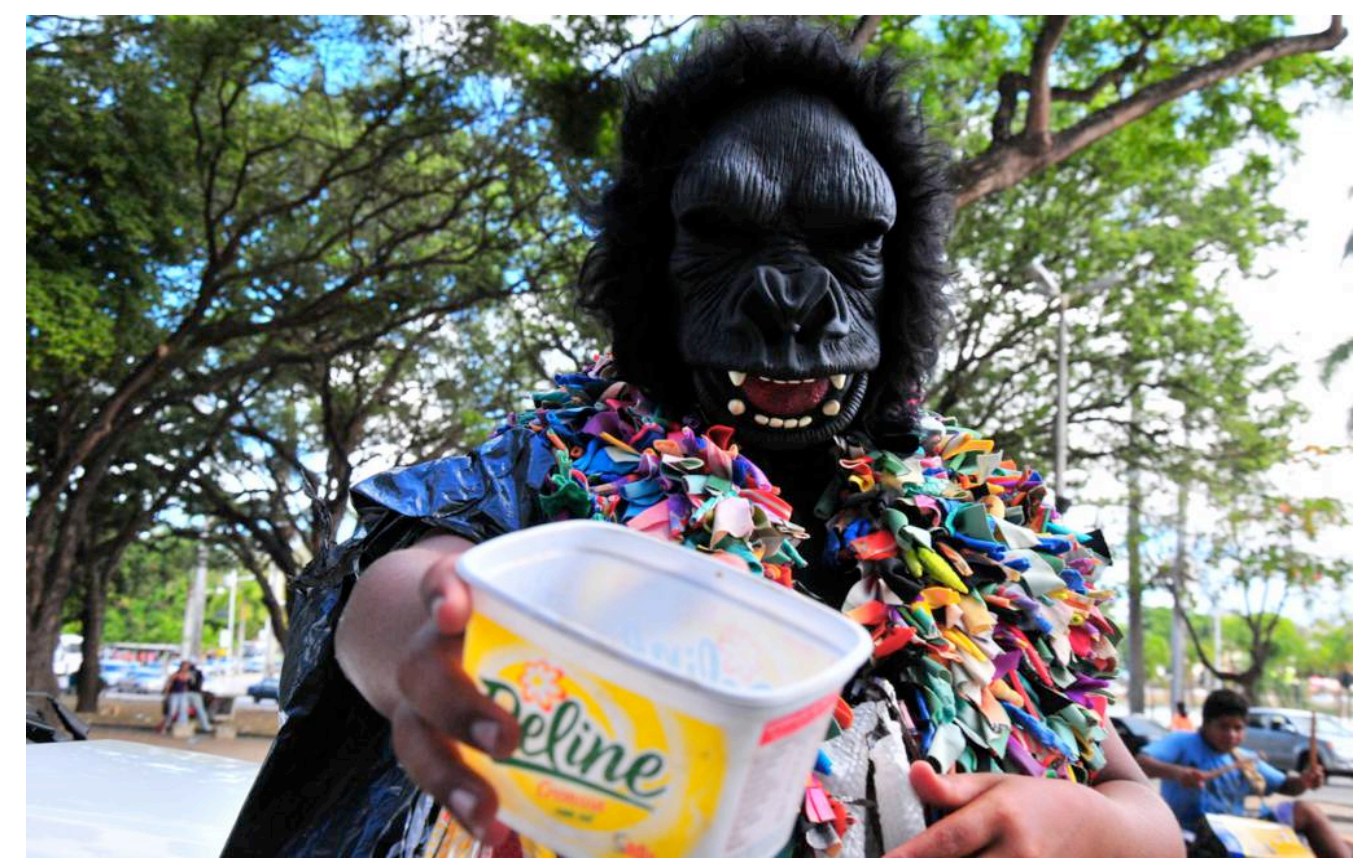

Figura 1: "la ursa" -centro de João Pessoa-PB/ 2013

Fonte: Manodecarvalho

O "la ursa" ou "ala ursa" como é conhecida em João Pessoa, é um entretenimento da cultura local, formada por grupos de pessoas de diferentes idades que saem às ruas todos os anos, em diferentes bairros da cidade, às vésperas e durante os festejos carnavalescos em pequenos blocos de arrasto ${ }^{1}$. O personagem tradicional desse folguedo é representado pela figura de um urso "indomável" e brincalhão, mas que também pode

\footnotetext{
${ }^{1}$ Bloco de arrasto: grupo de pessoas que tocam instrumentos musicais percussivos e ou de sopro se deslocando a pé pelas ruas de um lugar para outro. NDA.

Revista Digital do LAV - Santa Maria - vol. 8, n.4, p. 122-135 - Jan./Abr.2015 ISSN 1983-7348
} 
vir representado pela imagem do macaco ou até mesmo personagem de filme de terror exibidos em seriados norte-americanos.

Acompanhados por uma batucada, e embalados por um ritmo pulsante, desfilam pelas ruas, calçadas de casas, cruzamentos, semáforos, praças, avenidas, feira livre, e em todo o espaço disponível, público ou privado, ao som de instrumentos sonoros percussivos profissionais ou artesanais.



Figura 2: "la ursa" espontâneo bairro Rangel 2013

Fonte : Arquivo pessoal

O produto que o "la ursa" vende é o entretenimento seja ele por meio formal através de um contrato de prestação de serviços ou informal quando em contato direto com o transeunte. Para isso, o folguedo utiliza de artifícios provocativos e peripécias que desperte a atenção do público como, zombar, tripudiar, fazer graça, meter medo ou assustar, através de performance coreográfica, dança e brincadeiras, afim de envolver a participação da popular nessa diversão momentânea, e assim, adquirir alguns "trocados". Um acessório característico desse personagem é uma cuia carregada em uma das mãos ou um outro objeto que faça a função da mesma, ou seja, proporcione ao público uma mensagem direta de pedido financeiro quando direcionada ao transeunte, emitindo o som e imagem do tilintar das moedas em seu interior sem derruba-las. A função dessa é instigar o público alvo que encontra e aborda em seu trajeto a colaborar com doações em dinheiro com a brincadeira.

No "la ursa", a intervenção performática é executada geralmente pelo urso, mas pode também se estender ao grupo que o acompanha, para isso, utilizam como recursos as alegorias, seus próprios corpos e instrumentos para desenvolver alguma coreografia diferenciada por meio do improviso ou com movimentos estilizados e sincronizados do Revista Digital do LAV - Santa Maria - vol. 8, n.4, p. 122-135 - Jan./Abr.2015 ISSN 1983-7348 
urso. O figurino do "la ursa" atraí a atenção e curiosidade por onde passa. Composto por cores quentes, volume e tiras de tecidos ou fitas plásticas, esses materiais ressaltam os movimentos da vestimenta do personagem nas apresentações, destacando-se na sincronia com dança e manobras rítmicas da batucada, no uso de brincadeiras e gestos, seja ele agressivos ou meigos, proporcionando maior interação e entretenimento entre o público presente.

A construção e montagem desse folguedo, geralmente, não conta com farto recursos econômicos e com a existência de espaço definido, como uma sede própria. Sua feitura é realizada em qualquer lugar, por grupos de pessoas geralmente moradoras de periferia populosas e pouco grau de instrução formal, que realizam este trabalho muitas vezes de maneira improvisada e gratuita. Porém existem exceções, uma vez que temos também grupos de "la ursas" profissionais que dispõe de melhores condições financeiras e sede própria, o que facilita a contratação de mão de obra especializada de artesões e outros profissionais para desenvolver este tipo de serviço.

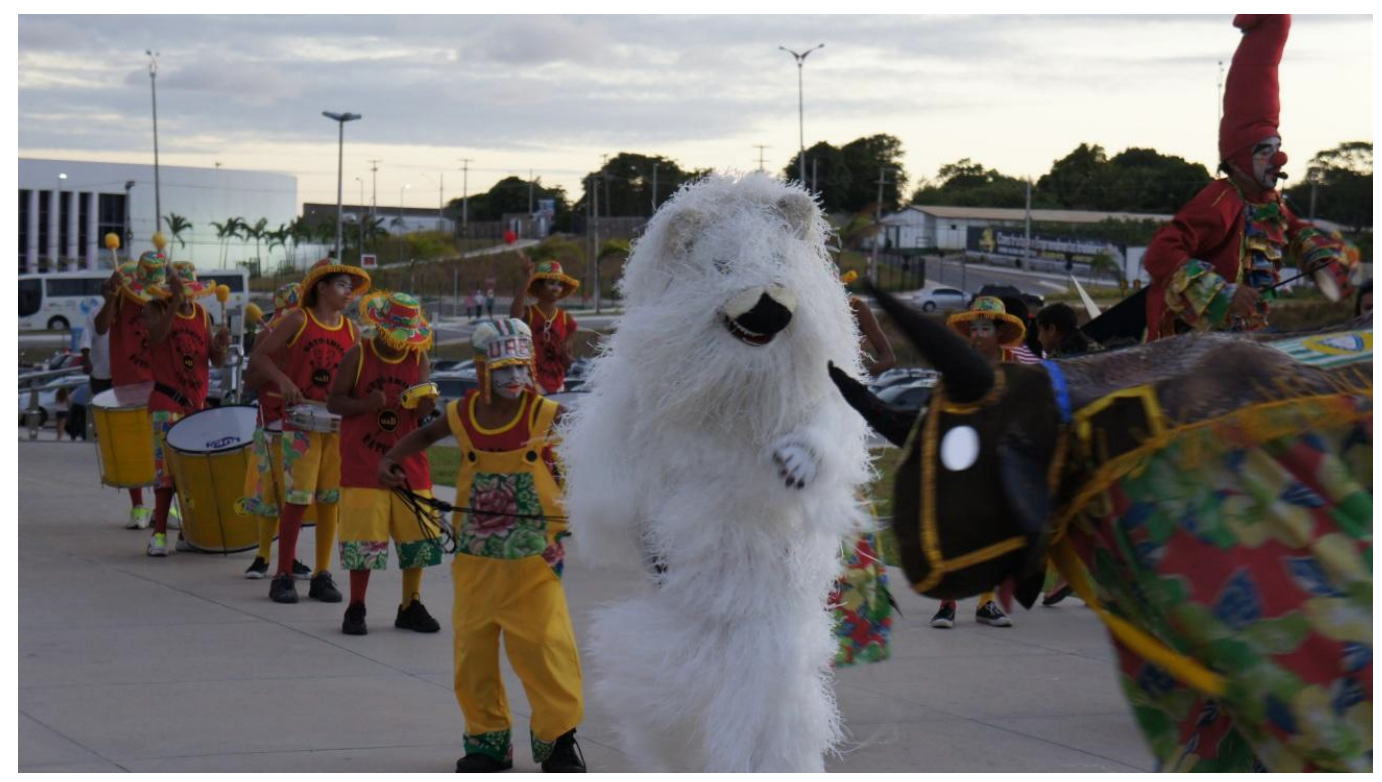

Figura 2: "la ursa" profissional "Urso amigo batucada"

Fonte: arquivo pessoal- Estação Ciência João Pessoa-PB

No entanto, na maioria dos casos este tipo de folguedo utiliza ruas, praças e as calçadas como locais de encontro, onde se reunirem e definem improvisadamente e gradativamente a montagem do espetáculo.

Inicialmente verificamos que a rua, as calçadas e as praças para a maioria desses grupos exercem o papel da sede, escritório, oficina, atuando como espaço de integração de pessoas e ambiente de trabalho, pesquisa, reunião. Neste caso, estar na rua é estar 
sujeito às regras da sobrevivência, "desprotegido" em relação ao conforto e segurança da sede. Assim, é no ambiente da rua onde tudo acontece e termina. Nela ocorrem os encontros, as conversas, divergências, as ideias e a definição dos personagens do "la ursa". A rua é o lugar onde se procura e se encontra materiais, pessoas, mão de obra e desafios a serem vencidos e que dará vida as fantasias e instrumentos musicais do folguedo.

A rua também atua como espaço onde se decide à hierarquia de poder nos grupos espontâneos de "la ursa", lugar de laser e de conflito, utilizada estrategicamente também como abrigo e esconderijo para grupos menores de "la ursa" guardarem instrumentos improvisados e não sucumbir a conflitos outros grupos maiores. Além disso, a rua proporciona também rota de fuga alternativa para que os brincantes escapem dos órgãos de repressão institucionalizados, além de fornecer acesso direto a seu público alvo para que o entretenimento conquiste "remuneração".

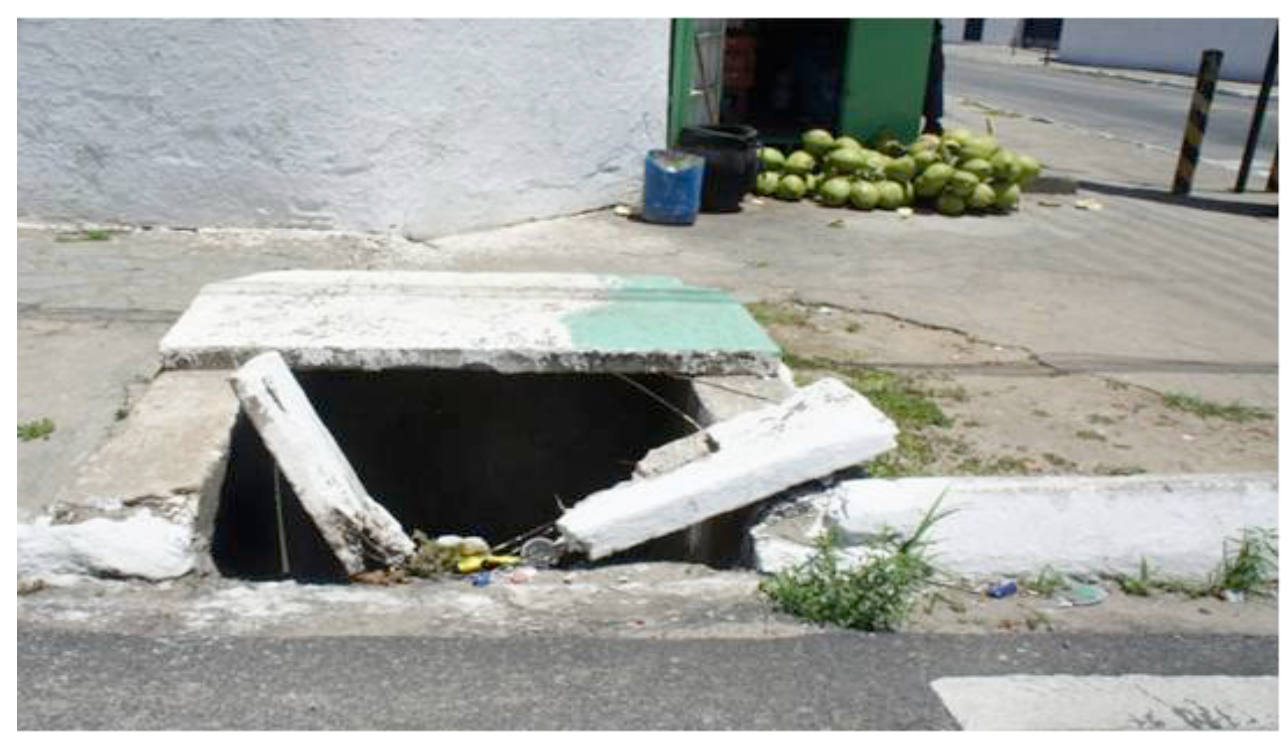

Figura 3: esconderijo de instrumento de "la ursa"-Rangel/2013

Fonte: arquivo pessoal

É importante frisar o papel social que o "la ursa" desempenha culturalmente ao potencializar a realização de atividades no campo da aprendizagem informal na produção de visualidades para todo tipo de público. Como um entretenimento, este folguedo pode ser visto como uma forma de promover a inclusão temporária entre diferentes classes sociais na valorização e difusão dos costumes e tradições carnavalescas da cultura local. A notoriedade das visualidades do "la ursa", pode ser explicitada tanto na produção de sentido de suas performances e coreografias, como também na construção dos artefatos estéticos e musicais que compõem a folgança. 
Também podemos observar a folgança como uma manifestação cultural transgressora das normas sociais, haja vista que, em sua maioria, os seus integrantes não fazem uso de local específico para realizar a brincadeira, adaptando sua atuação para qualquer lugar e a qualquer hora. Além disso, muitas crianças e adolescentes que brincam o "la ursa" saem as ruas sem autorização dos pais, "escondidos", utilizando vias públicas de grande tráfego de veículos e semáforo para se apresentarem. Algumas das falas do folguedo impetradas na brincadeira com o espectador instigam-no a assumir posicionamentos na folgança, que pode ser o de colaborar com alguns trocados "dinheiro". Quando os espectadores colaboram passam a ser considerados "gente boa". Podem ser chamados de pirangueiro por não colaborar com o urso. Essa interação social provocativa, feita com sagacidade e maestria, demonstra uma das formas de irreverência social e malandragem deste folguedo para interagir com seu público.

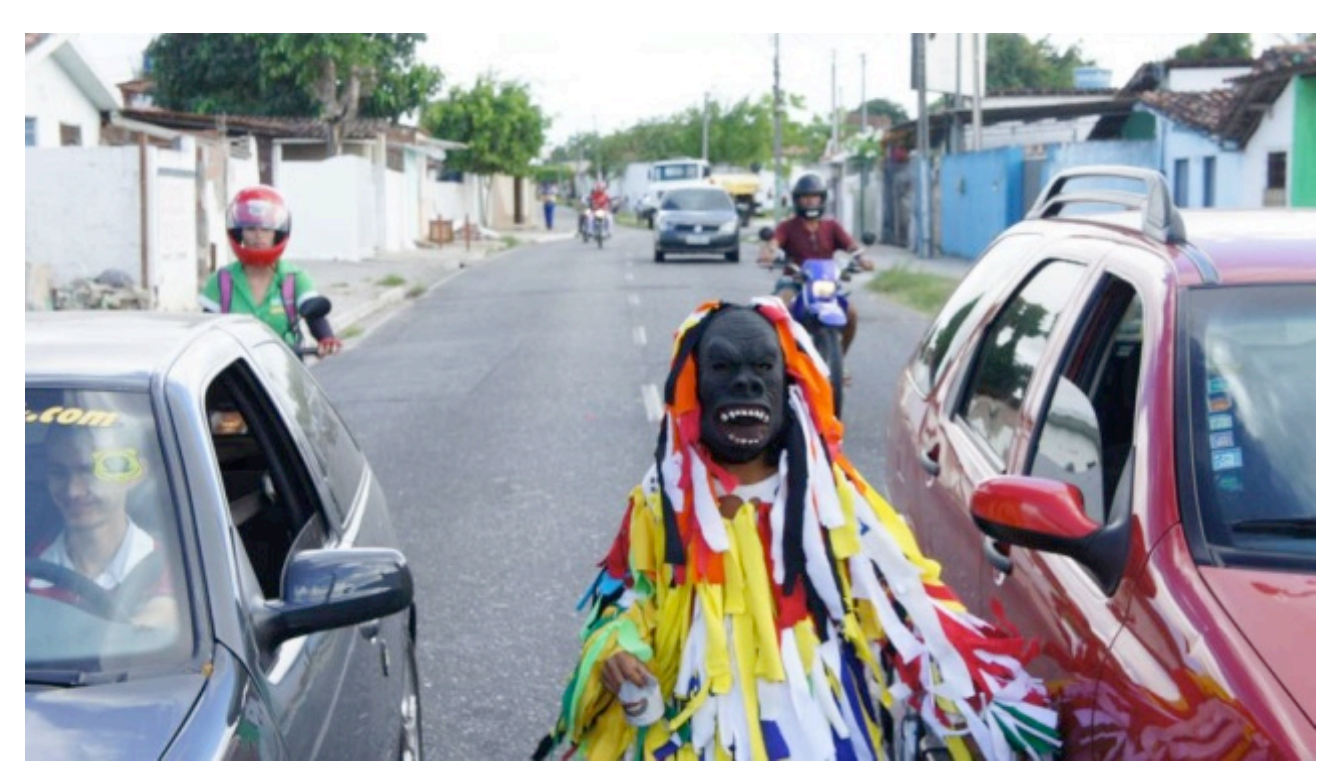

Figura 4: la ursa" Rangel- 2013

Fonte: arquivo pessoal

A estas peculiaridades performáticas do folguedo, chamamos neste trabalho, de peripécias transgressoras. Refirimo-nos a um conjunto de visualidades e performances irreverentes nas ações tradicionalmente impelidas do desejo de transgredir às normas sociais com a intenção de provocar susto, prazer, receber alguns dividendos financeiros, zombar e usufruir da rua como recurso didático informal e temporário de sobrevivência.

Em João Pessoa, existe um considerável número de grupos de "la ursas" que vêm se multiplicando todos os anos. Uma dessas razões, foi a oficialização da Federação de "la ursas" e a conquista e reconhecimento de participação dessa categoria no concurso do Carnaval Tradição da cidade, que trouxe estímulo à permanência e o surgimento de 
novos grupos de para brincar, e concorrer no desfile carnavalesco. O Carnaval Tradição é um dos eventos carnavalescos importantes que compõem o calendário oficial da capital. É nesse momento em que acontece o concurso no qual as "la ursas" participam dos desfiles, junto com outras categorias de entretenimento, como blocos de orquestra de frevo, tribos indígenas folclóricas e escolas de samba.

Esses desfiles acontecem todos os anos, no centro da cidade, na Avenida Duarte da Silveira, na capital paraibana. Durante três dias e no período da noite do carnaval, a partir das $18 \mathrm{~h}$, são realizadas as etapas desse concurso, com as agremiações concorrendo à classificação e à premiação a um dos três primeiros lugares, disputados por cada categoria, com base em critérios como: desempenho na avenida, criatividade, plasticidade, coreografia, ritmo, tempo de duração, integração com a plateia, arranjos, fantasias, enredo, entre outros. Nesse ritual de "celebração carnavalesca oficializada", há uma demarcação de território entre os grupos que desfilam, incluindo a plateia e os jurados. Cada setor ocupa lugares de destaque, mas em situações opostas e dentro de uma "ordem social" pré-estabelecida pelos palanques, arquibancadas e "passarela ou avenida", deixando bem evidente a relação de hierarquia entre todos os presentes. Dessa forma, o carnaval tradição se caracteriza como um espetáculo que restringe a participação do espectador, que pode apenas observar, aplaudir, torcer ou documentar o espetáculo. Uma cerca e as arquibancadas reforçam a separação e o papel desses personagens durante esse evento.

Uma das categorias participantes do concurso do Carnaval Tradição são os grupos de "la ursa" profissionais, que contam com a publicação de editais disponibilizados pelo poder público, para financiar parcialmente, o custeio de recursos materiais desses grupos e as despesas com a produção do folguedo. Isso colabora para que as visualidades dos grupos participantes do evento, passem a assumir um caráter competitivo. Os grupos contratam equipes profissionais para trabalhar na produção do folguedo. A participação no Carnaval Tradição de João Pessoa/PB tem influenciado a produção imagética do "la ursa", uma vez que esses grupos participam de disputas cada vez mais acirradas a cada ano. Apresentam ao público e aos jurados novos referenciais estéticos e sonoros e exploram a avenida progressivamente, as visualidades em adereços, cores, coreografias e palavras de ordem e temas sociais. Também incluem outros personagens e até estandartes na construção e no desenvolvimento do folguedo.

Isso tem influenciado na produção imagética do "la ursa", que busca, a cada ano, produzir novos referenciais estéticos, sonoros e performáticos para impressionar o público e aos jurados. A inclusão de novos elementos estéticos e sonoros no corpo desse 
folguedo produz um hibridismo visual e cultural. Nesse sentido, o folguedo não é visto somente como entretenimento, mas também como uma forma de resistência para se manterem vivos e serem inseridos em contextos sociais oficiais de eventos para grandes massas.

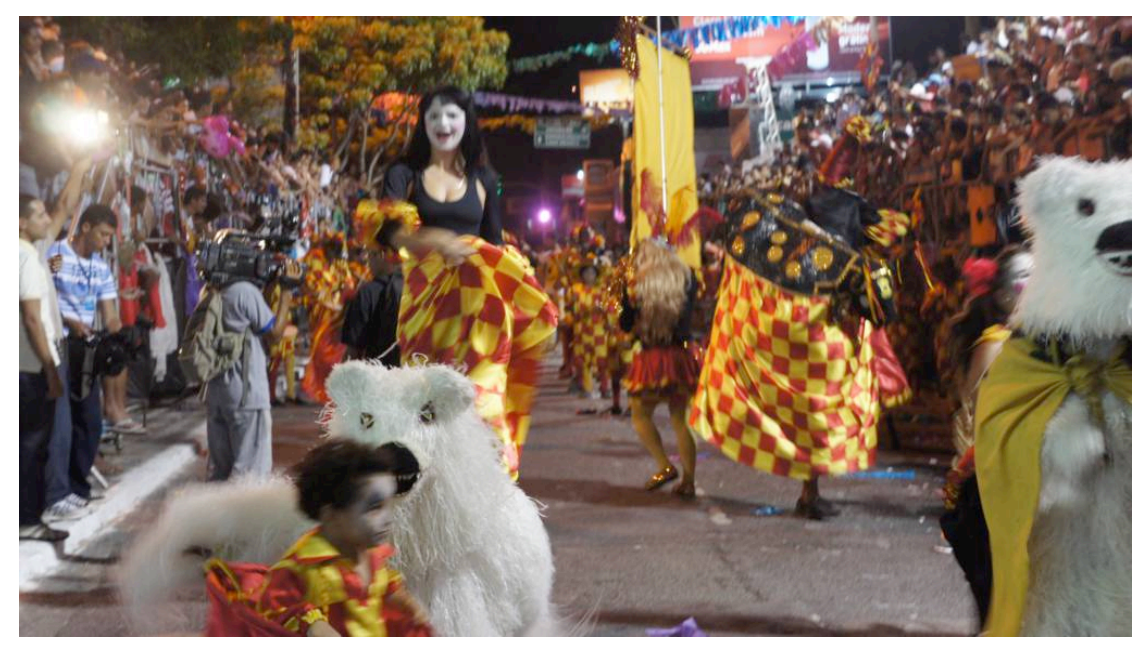

Figura 5: "urso amigo batucada" -Carnaval tradição Fonte: Arquivo pessoal- 2013/ João Pessoa-PB

A inclusão de novos elementos estéticos e sonoros no corpo desse folguedo produz um hibridismo visual e cultural. Nesse sentido, o folguedo não é visto somente como entretenimento, mas também como uma forma de resistência para se manterem vivos e serem inseridos em contextos sociais oficiais de eventos para grandes massas.

O impacto visual apresentado no "la ursa", com a implantação de mais elementos estéticos em sua composição, como estandarte, burrinhas ${ }^{2}$, pernas de pau, entre outras alegorias, traz para o grupo mais visibilidade e certa confusão conceitual. Nesse caso, o folguedo amplia seu potencial, inserindo mais coreografias na competição. Incrementam com vários elementos circenses no corpo do folguedo, ampliando a visibilidade de seus integrantes, da vestimenta padronizada. Durante esse evento e em outros, passam a assumir a categoria de espetáculo, de entretenimento, de um show business, adaptando sua "cuia" a um contrato formal de prestação de serviço impresso.

Ressalte-se, no entanto, que esse novo formato da imagem do folguedo modifica a maneira de compor e de conceber o "la ursa", porque o "urso" assume o caráter dócil, brincalhão, adestrado, subserviente, de objeto de decoração ou bichinho carinhoso "fofo", em detrimento de outras características culturais também marcantes desse

\footnotetext{
2 Burrinhas: alegorias que têm a forma de um animal conhecido por "burro ou jumento", construídas com pano, armação em arame, espuma e papel machê, dentro das quais uma pessoa desenvolve coreografias. São muito utilizadas no folguedo do "bumba meu boi". (N.A)
} 
bailado. A irreverência apresentada na abordagem do público na rua, no semáforo, que demonstra mais liberdade de expressão do personagem em seu modo de provocar e interagir com o público é modificada. Seus refrãos característicos são silenciados e dão lugar ao espetáculo percussivo e coreográfico que atenda ao novo contexto socioeconômico e político assumido na brincadeira e se adéque a ele. De certa maneira, essa alteração em alguns aspectos formais do folguedo faz parte de uma lógica de sobrevivência social e cultural que, segundo Marcos Ayala dizem respeito às

práticas culturais populares como sobrevivência do passado no presente, pois independentemente de suas origens, mais remotas ou mais recentes, mais próximas ou mais distantes geograficamente, elas se reproduzem e atuam como parte de um processo histórico e social que lhes dá sentido no presente, que as transforma e faz com que ganhem novos significados. (AYALA.1987, p.52)

Essas visualidades refletem uma visão geral e comum aos grupos de "la ursa", que atuam espontaneamente na cidade de João Pessoa/PB. Mostram que nosso olhar sobre eles não se limita à plasticidade estética e à sonoridade, mas ao conjunto de valores relacionados com o processo educacional que envolve modos de ver, sentir e agir produzidos pela interação entre o público e o conjunto imagético. É um modo de procurar entender essas práticas culturais, observando-as e analisando-as também pela ótica das ciências humanas e sociais, a partir do cotidiano compartilhado pela coexistência de quem as faz e por quem as vê.

Assim, no contexto da folgança, a figura do "urso" assume diferentes papéis sociais, de acordo com a política e o discurso do grupo social no qual se inserem, podendo representar aspectos dócil, provocativo, arredio, irreverente, brincalhão, pedinte, libidinoso e desprezível, entre outras. Essas características peculiares do folguedo funcionam como o motor que impulsiona a brincadeira, na qual a máscara, a vestimenta, a composição rítmica e performática, bem como seu discurso dialogam com peculiaridades referente às condições socioeconômicas de seus componentes.

Há grupos de "la ursa" do bairro Rangel e de outras comunidades periféricas que constroem seus folguedos na cidade de João Pessoa/PB, utilizando recursos improvisados. a partir de roupas velhas, sacos de estopa ou nylon, cortados em tiras e presas por costuras umas às outras, ou a uma calça e a uma camisa usada e cheia de buracos. Com máscaras compradas em lojas ou produzidas a partir de papelão, papel marche ou sacos plásticos, nos quais são feitos furos ou buracos para os olhos, para a boca e para o nariz do personagem e um cordão utilizado como rédeas para segurar ou guiar o urso. 
Os "la ursas" espontâneos também fazem uso de uma variedade de recursos alternativos e materiais recicláveis que utilizam como instrumentos sonoros, são eles: lata, baldes plásticos, pedaços de madeira, de ferro, de cano, entre outros objetos que emitam uma boa sonoridade. É possível dizer que compõem e exploram novos meios de inserção social e formas de resistência estéticas, musicais e econômicas, produzindo um discurso político que "servem de fundamento para uma proposta educativa voltada à 'compreensão crítica e performática da cultura visual'.[...].Uma perspectiva [...] em permanente construção". (HERNÁNDEZ, 2007. p. 79).

Deste modo, vejo esse folguedo como uma oportunidade de investigação, repleta de imagens, situações e episódios nos quais as brincadeiras, com as máscaras, a utilização dos artefatos sonoros, a irreverência e o entretenimento, ocupam lugar de destaque nos festejos carnavalescos da capital da Paraíba.

Nesta pesquisa, compartilhamos com o ponto de vista de Renato Ortiz de que 'ser diferente não basta'. É preciso mostrar que há identificação, visto que "não existe uma identidade autêntica, mas uma pluralidade de identidades, construídas por diferentes grupos sociais em diferentes momentos históricos" (ORTIZ, 1994, p.8).

Assim, algumas questões me levaram a buscar respostas para um melhor entendimento sobre as formas de manutenção, sobrevivência e inserção social do folguedo "la ursa" nas manifestações carnavalescas de João Pessoa, foram: o que leva essas pessoas, todos os anos, a fazerem e levarem às ruas, o folguedo "la ursa"? Quais os motivos que os fazem se articular, planejar e desenvolver as visualidades da folgança? Como veem a sociedade e como são vistos por ela? Que tipo de relação o "la ursa" mantém com o sistema social? Que relação de saber e diálogo o sistema educacional formal desempenha para o desenvolvimento desse entretenimento na contemporaneidade? Como utilizar tais interpretações como narrativa para estudos da cultura visual?

Estas questões se entrecruzam e, além de criarem inquietações, criam expectativas para se compreender a complexa teia de significados, que se constrói em torno dessa manifestação cultural e, mais especificamente, das visualidades do folguedo "la ursa" e dos festejos de Momo, como multiplicidade interpretativa, simbolicamente significativa, que cria relações de saber e de poder.

Optou-se, ainda, por um estudo de caso porque se apresenta como um instrumento metodológico de grande utilidade, apresentando vantagens, como: o estímulo às novas descobertas, a ênfase na compreensão de uma unidade e a simplicidade dos 
procedimentos.

Para o desenvolvimento da pesquisa, várias técnicas de coletas de dados foram necessárias, especialmente as entrevistas, os registros fotográficos e as observações diretas durante a preparação e a atuação do folguedo em foco.

A abordagem qualitativa do tipo etnográfica enfatiza a investigação interpretativa e nos instiga a fazer uso do registro da visualidade, da entrevista, bem como da observação participante, tendo como determinante o estudo de caso.

O universo da pesquisa foi constituído por um grupo de adolescentes, supostamente com idade entre 12 e 18 anos, moradores do bairro Rangel, da cidade de João Pessoa/PB, e de outro, que inclui adultos, que participa do concurso do "carnaval tradição". A delimitação da faixa etária partiu inicialmente de observações sobre a grande incidência de adolescentes envolvidos na construção deste folguedo.

Em razão do exposto, entende-se a importância de investigar o "la ursa", sob a ótica da pesquisa qualitativa do tipo etnográfica, haja vista que se trata de uma produção da cultura local, envolta em visualidades, plasticidades, dramaticidades em interação com o cotidiano. É um folguedo que colabora na construção e desconstrução social e pode ser analisada por diferentes perspectivas e campos de conhecimentos e estudos, como é o caso da cultura visual.

Nesta pesquisa, enfocamos a importância dessa folgança no processo de desenvolvimento da educação informal e não formal em alguns estados da Região Nordeste do Brasil. Verificamos que entretenimentos socioculturais dessa natureza influenciam maneiras de comportamento de pessoas, seus modos de agir, sentir e se expressar e que a convivência e a participação da sociedade com esse rito traz à luz novos olhares sobre a maneira de enxergar, respeitar e entender as transgressões promovidas por essa folgança, muitas vezes vista, equivocadamente, de forma preconceituosa, sempre que ela se sobressai na relação de valores e padrões "morais" socialmente estabelecidos.

Observamos que as regras de comportamento social desses ritos são determinadas segundo a subjetividade de cada um, quer o seja de cunho religioso, cívico ou festivo, e que desenvolvimento performático e discursivo estará atrelado diretamente à relação dos padrões estabelecidos pelo rito.

O estudo apontou que o "la ursa" é um rito de natureza dramática da cultura popular que 
acontece às vésperas e durante o período carnavalesco e atua tanto no seguimento formal oficial quanto espontaneamente ou na informalidade, com forte participação em estados como Pernambuco e Paraíba. Que esses ritos se diferenciam de um para outro, e o folguedo "la ursa" transita entre a ordem estabelecida e uma desordem social.

Esta pesquisa também identificou as principais características que diferenciam e identificam o formato e modo de agir, atuar e propósito dos dois grupos de "la ursa", investigados, um Espontâneo e outro Profissional.

\begin{tabular}{|c|c|c|}
\hline $\begin{array}{l}\text { Macaco Louco do Rangel } \\
\text { Espontâneo }\end{array}$ & $\mathrm{X}$ & $\begin{array}{l}\text { "urso" Amigo Batucada } \\
\text { Profissional }\end{array}$ \\
\hline Produz a própria fantasia. & & $\begin{array}{l}\text { Compra ou encomenda a } \\
\text { fantasia. }\end{array}$ \\
\hline $\begin{array}{l}\text { Não participa de editais culturais, não } \\
\text { inscreve projeto nem é patrocinado. }\end{array}$ & & $\begin{array}{l}\text { Participa, inscreve projeto no Fundo de } \\
\text { Incentivo Cultural-FIC-JP/PB, FUNJOPE, } \\
\text { entre outros. }\end{array}$ \\
\hline Não tem lugar certo de onde sair. & & Sai de um local pré-estabelecido. \\
\hline Utiliza cuia. & & Utiliza contrato. \\
\hline Utiliza frases e provocações. & & Não utiliza. \\
\hline $\begin{array}{l}\text { Saem sem o conhecimento dos } \\
\text { familiares. }\end{array}$ & & Sai com apoio dos familiares. \\
\hline Produz seus instrumentos. & & Compra seus instrumentos. \\
\hline Pede dinheiro aos transeuntes. & & Não pede. \\
\hline Provoca o poder público. & & Não provoca. \\
\hline Não participa do Carnaval Tradição. & & Participa. \\
\hline Sai às vésperas e durante o carnaval. & & Sai o ano inteiro. \\
\hline $\begin{array}{l}\text { Utiliza ruas e calçadas para produzir } \\
\text { suas fantasias. }\end{array}$ & & Trabalha em sede comunitária no bairro. \\
\hline Não promove oficinas. & & Promove oficinas de percussão. \\
\hline O urso é sua única alegoria. & & Utiliza diversas alegorias além do urso. \\
\hline
\end{tabular}

No contexto dessa pesquisa, considero a ação cultural, que cada grupo de "la ursa" desempenha, como uma dimensão estética e imagética de profunda importância para as manifestações culturais da cidade de João Pessoa. Vejo-as como formas de resistência social que produzem suas próprias motivações econômicas, políticas e sociais. Diferenciam-se um dos outros de acordo com seus interesses, formas de penetração e inserção no sistema capitalista.

Participar dessa folgança é uma oportunidade para o indivíduo mostrar sua identidade lúdica, imaginativa, irreverente e provocadora. A cada ano, essa força inventiva se 
revitaliza, gerando novas imagens e recombinações que reúnem o velho e o novo, a tradição e a contemporaneidade. Isto evidencia o processo de confecção no uso e na função da alegoria, das performances do folguedo, do jogo de palavras e de suas visualidades para produzir construções sociais, materiais e simbólicas.

Dessa forma concluímos que o folguedo "la ursa" faz parte do rito carnavalesco, uma vez que pensar o carnaval é observar o ser humano explorando seus impulsos mais íntimos, críticos e audaciosos. É lidar com ambiguidades, religiosidades, prazeres e adentrar em caminhos comuns e imprevisíveis. É se deixar guiar pelo ritmo, pela alegria, pelo êxtase, pelo corpo, por valores que não são unicamente brasileiros, mas também de uma versão cristã. São valores, tradições e possibilidades que coexistem em um tempo e espaço determinados para iniciar e terminar.

\section{Referências}

ANDRÉ, Maria Eliza Dalmazo Afonso de. Etnografia da prática escolar. Papirus, Campinas, São Paulo, 1995.

AYALA, Marcos e AYALA, Maria Inês Novais. Cultura Popular no Brasil. Ática, São Paulo, 2006.

HERNÁNDEZ, Fernando. Catadores da cultura visual: proposta para uma nova narrativa educacional. Porto Alegre: Mediação, 2007.

LEAL, Wills. No tempo do lança-perfume ou a história do carnaval na/ da cidade de João Pessoa. 2 ed. João Pessoa: [s.n.], 2000.

ORTIZ, Renato. Cultura brasileira e identidade nacional. São Paulo: Brasiliense, 1994.

REAL, Katarina. O folclore no carnaval do Recife. Rio de Janeiro: Companhia de Defesa do Folclore Brasileiro, v. 2, 1967. (coleção folclore brasileiro).

\footnotetext{
Camilo de Figueiredo Aranha. Mestre pelo Programa de Pós-graduação das Universidades Federais de Pernambuco e Paraíba- PPGAV-UFPE/ UFPB. Membro do grupo de Pesquisa em Artes Visuais -GPAV-UFPB. Especialista em Arte e Educação Física na Infância pela UFRN, graduado em Educação Artística (Artes plásticas) -UFPB. Professor de Artes da Secretaria de Educação Municipal da cidade do Natal- RN, Secretário de Meio Ambiente da Associação dos Amigos da Cultura, Arte e Meio Ambiente- AACAMA. E.mail: camilloaranha@gmail.com
} 
Recebido em: 14/11/2014

Aprovado em: 20/03/2015 